\title{
Covid 19: Social, Financial and Economic Implications
}

\author{
Sonali Bhattacharya ${ }^{1}$, Ciorstan Smark ${ }^{2}$ and Monir Mir $^{3}$
}

\section{Editorial}

In this special issue we have included research papers presented in the first S-TEAM 2020 (SCMHRD - TECHNOLOGY, ECONOMICS, ANALYTICS \& MANAGEMEMENT) CONFERENCE 2020 organized virtually by Symbiosis Centre for Management and Human Resource Development, a constituent of Symbiosis International University, Pune, INDIA held from 17th to 22nd August, 2020. The theme of the Conference was "Changing Paradigms of Management during and after a Global Crisis". Any situation of the crisis has several social sciences and inter-disciplinary \& transdisciplinary dimensions.

COVID-19 pandemic has forced business organizations, nations and governments to rethink on the predictive analysis of occurrence of such hazards and their social, economic and financial implications world over. Such challenging situations call for collaborative efforts between academia, research fraternity, media, and voluntary organizations to rhetorically 'try and douse the flames'. Resolute action is required from various government agencies and health care service providers to promote sustainable healthy lifestyles, managing economic challenges, and nurturing scientific culture among masses and societies. Some nations perform better than others in managing the disaster and providing essential services owing to their better standards of public health infrastructure and sufficiency in financial, human and technical resources (Ortu et al, 2008; Oshitani, Kamigaki \& Suzuki, 2008; Fedson, 2009)., Global financial markets, institutions and firms have observed many crises in the past. Having learnt its lessons, they have adequately adapted themselves to face similar eventualities in the future. Some of those crises were systematic and impacted the whole world. Whereas, some were specific to firms, institution and markets. These crises often have ended up causing financial markets to crash, generate high volatility, and lead to corporate failures owing to financial instability. Sometimes, even to the extent of raking up scandals due to inability of the leadership to efficiently manage the crisis. However, financial markets have never ignored the contagion effect. Post the global financial crisis of 2007-08, markets and institutions brought about many changes. Their preference to trade on the path of sustainable financial performance lead to: the formation of BASEL III guidelines, socially responsible investing, impact investing, digitization of financial institutions, payments \& settlements and stringent corporate governance norms. Recent researches have focused on

\footnotetext{
${ }^{1}$ Symbiosis Centre for Management \& Human Resource Development, Symbiosis International (Deemed University), Pune-411057, India. Sonali_bhattacharya@scmhrd.edu

${ }^{2}$ University of Wollongong, Australia

${ }^{3}$ University of Canberra, Australia
} 
exploring the vulnerability of nations towards hazards and the macroeconomic and social antecedents of such events (Marulanda Fraume, et al 2020). Social media and Big data analytics are being used for undertaking sentimental analysis of apathy of victims of such events and suggest requisite structural, technical and financial framework that will expedite the disaster recovery system (Malawani, Nurmandi, Purnomo., Rahman, ,2020). Studies are being undertaken on regional resilience, entrepreneurial opportunity recognition and stakeholder engagement during disaster (Gur, Bendickson, Madden, McDowell, 2020). Studies also have focused in on willingness and capabilities: physical, social and psychological, of government and community to participate in risk reduction and mitigation (Miao, Chen, Lu, Abrigo, 2020). Preventive, responsive and adaptive capacities of the communities, institutions and territory can be enhanced through appropriate design, planning, investment, execution and evaluation of various public and private initiatives. Studies have shown CSR activities can positively impact recovery during disaster relief operations which further can be enhanced through improvement in quality of information (Behl and Datta, 2019). The pandemic like situations may also likely to create psychological impact due to resource lost, unemployment, job loss and debt (Clay and Greer, 2019). According to Conservation of Resources (COR) theory, change at work can be threatening because it holds a risk of losing valued outcomes (Dent \& Goldberg, 1999; Hobfoll \& Shirom, 2001). Coming to terms with such changes can be very difficult. However, the same can be facilitated by the meaning-making process by the individual concerned (Sonenshein \& Dholakia, 2012; Van den Heuvel et al., 2009).

Organizational work setups are forced to shift to new arrangements, working from home is going to be a work practice for many organizations (Bhattacharya and Mittal, 2020). Aryee, 1992; Geurts, Rutte, \& Peeters, 1999; Wallace, (1999) suggested that work overload is one of the most important factor determine Work Happiness Index. Another aspect of work which is going to be impacted significantly is the communication process, which virtual meetings becoming the reality, the need of transparent and continuance communication will be more than ever (Eisenberg, 1984). This may perpetually alter the ways of learning, transacting, and working of people.

Labour force, supply chain management, consumer behavior and marketing has also undergone a change (Hakovirta and Denuwara, 2020) Outcome as a service model can be the new supply chain model in which product delivery will be packaged with services thereof based on customer desire, most effectively through Digital platform. In tourism industry slow and smart tourism will be the new mantra (Wen, Kozak, Yang, Liu, 2020). Marketing strategy has become more agile to capture new market and new customer. Online communication has become the most dominant marketing communication channel (He and Harris, 2020). Customers' preferences have shifted towards local market outlets, local products from global brands.

The 336 papers presented in the conference discussed some of these issues. The present collection of seven research papers investigated the socio-economic, financial and psychological impacts of Covid 19 crisis through cross-disciplinary lens.

The first research paper by Mittal and Sharma (2021) studied the impact of stock prices in the healthcare and pharmaceutical sector during Covid 19 by using event management technique. Closing prices were observed for 233 days from $15^{\text {th }}$ May 2019 to $24^{\text {th }}$ April 2020. Abnormal returns were observed during the period. In the second research paper, the authors, Vinod and Sharma (2021), by taking Airbnb and Uber as case companies, studied the impact of Covid 19 on the level of consumers' use of these shared services. It was found consumers, post Covid have 
become more concerned towards safety and protection and hence use of these shared services has reduced. The research paper by Karthik and Sinha (2021) highlight that Covid has adversely affected the shared economy due to growing concern for safety, hygiene, higher operational cost and consumers' growing acceptance of work-from home concept. Lahiri and Sinha (2021) explored socio-economic impact of Covid 19 through their qualitative studies in two metropolis of India and found that people in general avoided leaving home other than emergencies especially medical emergencies. Government's performance at the national level during the crisis was found to be below expectations though some of the initiatives taken by local governments were well appreciated. Covid has been perceived to have impacted adversely livelihood, caused loss of clients or businesses and hampered supply chain network, Online education experience was found to be dissatisfactory due to internet issues, lack of concentration, time management, lack of peer interaction, home-work conflict and inappropriate mode of assessment and have caused adverse psychological impact on learners. Phadnis et al. (2021) studied the behaviour of Standard and Poor Indices over seven global events: South East Asia Crisis, Dotcom bust, 9/11 attacks, 2008 crisis, European Debt Crisis, Brexit and Covid within the selected period from FY 1997 to FY 2019. It was observed that there is a set of pre-shocks in the index values before the maximum drop in any given crisis. Gurubaxani and Gupte (2011) studied the impact of Covid on individual investors' investment behaviour under Systematic Investment Plan in a small town in Madhya Pradesh, India. It was found that there was significant drop in level of investment post Covid across demographics. Kuknur and Bhattacharya(2021) used a mixed method approach to investigate how a diverse workforce can be leveraged through inclusion to benefit the organization in times of global crisis. It was found that Organizational Inclusion is positively associated with Organizational Citizenship Behaviour and Organization Based Self Esteem moderated by Inclusive Leadership.

\section{References}

Aryee, S. (1992). Antecedents and outcomes of work- family conflict among married professional women: Evidence from Singapore. Human Relations, 45, 813- 837.

Behl, A., \& Dutta, P. (2019). Social and financial aid for disaster relief operations using CSR and crowdfunding. Benchmarking: An International Journal.

Bendickson, J. S., Madden, L., McDowell, W. C., \& Gur, F. A. (2020). Entrepreneurial opportunity recognition in the face of disasters. International Journal of Entrepreneurial Behavior \& Research.

Bhattacharya, S., \& Mittal, P. (2020). The Impact of Individual Needs on Employee Performance while Teleworking. Australasian Accounting, Business and Finance Journal, 14(5), 65doi:10.14453/aabfj.v14i5.585. DOI http://dx.doi.org/10.14453/aabfj.v14i5.5

Clay, L. A., \& Greer, A. (2019). Association between long-term stressors and mental health distress following the 2013 Moore tornado: a pilot study. Journal of Public Mental Health, 18(2), 124-134.

Dent, E. B., \& Goldberg, S. G. (1999). Challenging "resistance to change". The Journal of applied behavioral science, 35(1), 25-41.

Geurts, S., Rutte, C., \& Peeters, M. (1999). Antecedents and consequences of workhome interference among medical residents. Social Science \& Medicine, 48, 1135-1148.

Gurbaxani, Arpita and Gupte, Rajani, A Study on the Impact of COVID- 19 on Investor Behaviour of Individuals in a Small Town in the State of Madhya Pradesh, India, Australasian 
Accounting, Business and Finance Journal, 15(1), 2021, 70-92. doi:10.14453/aabfj.v15i1.6 http://dx.doi.org/10.14453/aabfj.v15i1.6

Hakovirta, M., \& Denuwara, N. (2020). How COVID-19 redefines the concept of sustainability. Haynes, K., Bird, D. K., \& Whittaker, J. (2020). Working outside 'the rules': Opportunities and challenges of community participation in risk reduction. International journal of disaster risk reduction, 44, 101396.

He, H., \& Harris, L. (2020). The Impact of Covid-19 Pandemic on Corporate Social Responsibility and Marketing Philosophy. Journal of Business Research.

Hobfoll, S. E. (2001). The influence of culture, community, and the nested-self in the stress process: advancing conservation of resources theory. Applied psychology, 50(3), 337-421.

Karthik, K. A. and Sinha, Manish, The Impact of Physical Distancing on the Sharing Economy, Australasian Accounting, Business and Finance Journal, 15(1), 2021, 22-36. doi:10.14453/aabfj.v15i1.3 http://dx.doi.org/10.14453/aabfj.v15i1.3

Lahiri, Shouvik and Sinha, Manish, A Study of the Socio-Economic Implications of the COVID19 Pandemic, Australasian Accounting, Business and Finance Journal, 15(1), 2021, 51 69. doi:10.14453/aabfj.v15i1.5 http://dx.doi.org/10.14453/aabfj.v15i1.5

Kuknor, Sunanina and Bhattacharya, S, Organizational Inclusion and Leadership in Times of Global Crisis, Australasian Accounting, Business and Finance Journal, 15(1), 2021, 93 112. doi:10.14453/aabfj.v15i1.7 http://dx.doi.org/10.14453/aabfj.v15i1.7

Miao, Q., Chen, C., Lu, Y., \& Abrigo, M. (2020). Natural Disasters and Financial Implications for Subnational Governments: Evidence from China. Public Finance Review, 48(1), 72-101.

Mittal, Shivam and Sharma, Dipasha, The Impact of COVID-19 on Stock Returns of the Indian Healthcare and Pharmaceutical Sector, Australasian Accounting, Business and Finance Journal, 15(1), 2021, 5-21. doi:10.14453/aabfj.v15i1.2 http://dx.doi.org/10.14453/aabfj.v15i1.2

Phadnis, C, Joshi, S. and Sharma, D. (2021) A Study of the Effect of Black Swan Events on Stock Markets - and Developing a Model for Predicting and Responding to them Australasian Accounting, Business and Finance Journal, 15(1), 2021, 113-140. doi:10.14453/aabfj.v15i1.8 http://dx.doi.org/10.14453/aabfj.v15i1.8

Silva, N., \& Mena, C. (2020). Identifying the underlying risk factors of local communities in Chile. Disaster Prevention and Management: An International Journal.

Sonenshein, S., \& Dholakia, U. (2012). Explaining employee engagement with strategic change implementation: A meaning-making approach. Organization Science, 23(1), 1-23.

Vinod, Paul P. and Sharma, Dipasha, COVID-19 Impact on the Sharing Economy PostPandemic, Australasian Accounting, Business and Finance Journal, 15(1), 2021, 37-50. doi:10.14453/aabfj.v15i1.4 http://dx.doi.org/10.14453/aabfj.v15i1.4

Wallace, J. E. (1999). Work-to-nonwork conflict among married male and female lawyers. Journal of Organizational Behavior, 20, 797-816. 